\title{
Realismo y Relaciones Internacionales: una observación desde la historia de la ciencia y la epistemología
}

\author{
Realism and International Relations: an \\ observation from the history of science \\ and epistemology.
}

\author{
Daniel Blinder*
}

\begin{abstract}
RESUMEN
El presente artículo busca realizar un análisis sobre la argumentación de la Teoría Realista en Relaciones Internacionales. El Realismo presenta una batería de conceptos para entender el sistema internacional basado en el centralismo del Estado-Nación, un sistema internacional anárquico, el balance de poder y la autoayuda. En este trabajo nos proponemos recorrer la trayectoria de estos conceptos y preguntarnos si resultan pertinentes para entender la política internacional. Se encontrará que los argumentos que caracterizan las lecturas realistas trasladan conceptos pensados y difundidos en las ciencias de la naturaleza a partir del siglo xvi, cuyas lecturas de los asuntos naturales responden a visiones mecánicas del universo y se trasladan a la naturaleza humana y el comportamiento político entre las unidades estatales. Dada la prolífica producción de esta escuela de pensamiento, para hacer una lectura crítica descriptiva y explicativa, hemos seleccionado a: 1) Hans Morgenthau, quien se considera el fundador del Realismo académico, 2) Kenneth Waltz, quien planteó una lectura Neorealista desde una visión estructural, y por último 3)
\end{abstract}

Investigador del Consejo Nacional de Investigaciones Científicas y Técnicas (CONICET) en el Instituto de Estudios para el Desarrollo Productivo y la Innovación, Universidad Nacional de José Clemente Paz. Politólogo, Doctor en Ciencias Sociales, Universidad de Buenos Aires. Investigador en Política de Ciencia, Tecnología y Relaciones Internacionales. ORCID: https:// orcid.org/0000-0002-9318-7040. Correo electrónico: dblinder@unpaz.edu.ar. Recibido: 14 de agosto de 2020; Modificaciones: 2 de diciembre de 2020; Aceptado: 14 de enero de 2021. 
Henry Kissinger, a quien se considera un realista como hacedor de política en la función de gobierno. En una primera parte de este trabajo analizaremos el contexto en que surgieron los conceptos que nutrieron al Realismo. Luego, rastrearemos el origen de estos conceptos que provienen de la filosofía natural que conformó el pensamiento moderno. Finalmente, extraemos algunas conclusiones sobre las implicaciones de pensar lo internacional con categorías y metafóricas provenientes de los orígenes epistemológicos de otras ciencias.

Palabras clave: Realismo - Naturaleza - Universo - Equilibrio Poder.

\section{ABSTRACT}

This article aims an analysis on the Realist theory arguments in International Relations. Realism presents several concepts to understand the international system based on the centralism of the Nation-State, an anarchical international environment, and the balance of, power. In this paper, I propose to read the trajectory of these concepts and ask if they are relevant to understand international politics. This work finds that Realism took concepts of the natural sciences from the 16th century. This kind of readings are mechanical visions of the universe and was transferred to human essence and nature, and to the political behavior among nations. Given the prolific production of this school of thought, we have selected to make a descriptive and explanatory reading to 1) Hans Morgenthau, who considers himself the founder of Academic Realism, 2) Kenneth Waltz, who proposed a Neorealist reading from a structural perspective, and finally 3) Henry Kissinger, who is considered a realist as a policymaker. Firstly, I analyze the context in which the concepts that nurtured Realism. Then, I track the origin of these concepts that come from the philosophy of nature that shaped modern scientific thought. Finally, I describe the implications of thinking the international arena with categories and metaphors from other sciences.

Keywords: Realism - Nature - Universe - Balance - Power. 


\section{INTRODUCCIÓN}

El presente trabajo se propone realizar un análisis crítico sobre la construcción de los argumentos de la teoría Realista de la la disciplina Relaciones Internacionales. El realismo, que tiene distintos exponentes teóricos y subcorrientes internas y debates, construye un marco para analizar la realidad en la que, básicamente, presenta un modelo cuyos conceptos principales son el centralismo del Estado-Nación, el sistema internacional anárquico, el balance de poder, y la autoayuda. ¿De dónde provienen estos conceptos? ¿Son pertinentes para comprender el funcionamiento de la política internacional? ¿Es posible trasladar conceptos creados para entender fenómenos internacionales, para entender el funcionamiento de un ecosistema natural, el funcionamiento del átomo o la óptica? De la misma manera que intuitivamente responderíamos que no esta última pregunta, ¿̨por qué conceptos que provienen de las visiones mecánicas del universo del Renacimiento y de debates de aristotélicos sobre la naturaleza explicarían el comportamiento político entre Estados?

Dada la prolífica producción de los exponentes de esta corriente de pensamiento, y lo inabarcable de la misma para un ensayo de esta naturaleza, para la confección del presente trabajo se realiza una selección metodológica intencional de quienes consideramos sus mayores exponentes: Morgenthau,
Waltz y Kissinger. Si bien es cierto que la teoría Realista tiene tantos matices y expresiones como exponentes, los presupuestos básicos se pueden encontrar en estos tres autores que reconocen al ambiente internacional con las características y presunciones que aquí pretendemos analizar críticamente. El primero es quien introdujo el pensamiento Realista haciendo foco en el Estado (agencia), el segundo quien sistematizó con estatus científico positivista-estructuralista (estructura) y el tercero porque además de teórico fue un exponente teórico que llevó a cabo los principios básicos del Realismo. La selección, por lo tanto, es subjetiva en términos weberianos, pues con el mencionado criterio hacemos la selección, para luego hacer un análisis que busque la objetividad (Weber, 1993). El presente artículo no se propone ni hacer un exhaustivo estudio sobre el Realismo como escuela de pensamiento, su historia y su presente, ni todas las corrientes de pensamiento científica que en este confluyen. No obstante ello, se recurrirá a otros autores cuando la necesidad argumental sea demandada. Si nos proponemos trazar los orígenes de sus fundamentos teóricos y reflexionar sobre las consecuencias políticas, realizando una genealogía (Rodrigues, 2013) con los propios conceptos de los autores atribuidos como propios de la corriente teórica. 


\section{EQUILIBRIO UNIVERSAL}

En un sentido práctico, varios investigadores de las Relaciones Internacionales aseguran que las teorías de esta disciplina "pueden ser vistas como una caja de herramientas analítica que provee múltiples métodos y responder preguntas"(McGlinchey et al.,2017, p.2). Cada una de estas teorías puede aportar una mirada a una serie de hechos de la política internacional. Según el principal texto de Realismo académico, "el realismo político supone que la política, al igual que toda la sociedad, obedece a leyes objetivas que arraigan en la naturaleza humana. A los efectos de cualquier mejoramiento de la sociedad es necesario entender previamente las leyes que gobiernan la vida de esa sociedad. El funcionamiento de esas leyes es completamente ajeno al curso de nuestras preferencias; desafiarlas significa el riesgo de exponerse al fracaso" (Morgenthau, 1986, p.12).

Además, Morgenthau (1986, p.13) explica que "el elemento principal que permite al realismo político encontrar su rumbo en el panorama de la política internacional es el concepto de interés definido en términos de poder", y los estadistas podrían llevar a cabo políticas exteriores moralmente buenas o malas, pero lo que garantizará el éxito será la lectura correcta de la realidad de poder del sistema interestatal, siguiendo un curso "racional, objetivo y no emocional" (Morgenthau, 1986, p. 12).
Asimismo, según este clásico de la disciplina Relaciones Internacionales, existe un principio que rige entre naciones soberanas -que es la unidad de análisis del sistema internacional- y sin cuya presencia la disciplina carecería de todo sentido. El Estado en relación con los otros generan una especie de ecosistema en el cual "las aspiraciones de poder de varias naciones, cada una de ellas tratando de mantener o de quebrar el statu quo, llevan necesariamente a una configuración que se denomina 'equilibrio de poder' y a las políticas que procuran preservarlo" (Morgenthau, 1986, p.209). El equilibrio de poder es, según Morgenthau (1986, p.210), equivalente a balance y es utilizado en muchas otras ciencias como la física, la biología o la economía, la sociología y la ciencia política. De acuerdo a varios autores, la idea de equilibrio de poder es muy antigua, $y$ tiene distintas acepciones y valoraciones, y los realistas lo ponderan como un modo de organización social. El balance de poder impide el establecimiento de una hegemonía universal, asegura la estabilidad y seguridad mutua y prolongaba la paz (Dougherty $\&$ Pfaltzgraff, 1993, p.41-42).

La idea de orden mundial es lo que según Kissinger fue concebido en Europa Occidental como la Paz de Westfalia de 1648, siendo el sistema westfaliano la base de un orden basado en el equilibrio de poder, la soberanía estatal y la anarquía internacional. Pero 
Realismo y Relaciones Internacionales: una observación desde la historia de la ciencia y la epistemología

estos conceptos son concepciones de la circulación de ideas de la época, en la cual el poder político se secularizaba de la Iglesia y de sus ideas que empezaban a racionalizar el mundo, $y$ sentar las bases del pensamiento científico moderno. Westfalia estaba basada "en un sistema de estados independientes que se abstuvieran de interferir en los asuntos internos ajenos y controlaran mutuamente sus ambiciones a través de un equilibrio general del poder (...). A cada Estado se le asignó el atributo de poder soberano sobre su territorio" (Kissinger, 2016, p. 8).

1648 significó el establecimiento del Estado soberano, se acordó el derecho de cada país firmante a elegir su organización política y religión, y se protegió a las minorías religiosas. Es el comienzo de un sistema de relaciones internacionales con representaciones diplomáticas de cada Estado. Previamente existía una idea de unidad imperial o religiosa en la cual había un centro de poder legítimo (la Iglesia). A partir de Westfalia se buscó la multiplicidad para el orden común "sobre la base de reglas y límites consensuados, basado en la multiplicidad de poderes antes que en la dominación de un solo país" (Kissinger, 2016, p.36). De aquella multiplicidad nacía el equilibrio de poder.

"El equilibrio de poder puede desafiarse al menos de dos maneras: la primera es cuando un país importante aumenta su fuerza al extremo de amenazar con convertirse en hegemónico. La segunda tiene lugar cuando un Estado hasta entonces secundario quiere obtener el mismo rango que las grandes potencias" (Kissinger, 2016, p. 40).

Por su parte, Kenneth Waltz pretende un análisis Realista con criterios de cientificidad positivistas, pero partiendo de la idea de que el sistema internacional es análogo a una estructura. La teoría del "equilibrio del poder adecuadamente enunciada comienza por establecer presupuestos acerca de los Estados: son actores unitarios que, como mínimo, procuran su autopresevación y, como máximo, tienden al dominio universal" (Waltz, 1988a, p. 173). La centralidad del Estado es clave para entender el orden y "el equilibrio de poder prevalece siempre que se cumplan dos, y solo dos requerimientos: que el orden sea anárquico, y que esté poblado por unidades que deseen sobrevivir" (Waltz,1988a, p.178), siendo el resultado de acciones no coordinadas entre los Estados. Puede haber desbalances, pero el Estado, como actor, puede devolver el equilibrio (Waltz, 1990, p. 28). "La teoría no lleva a esperar que los Estados se comporten de maneras que resulten en la formación de equilibrios (...) Si los actores políticos se equilibran o no entre sí; si siguen o no la corriente, es algo que depende de la estructura del sistema" (Waltz,1988a, p.185). También el autor usa una metáfora biológica que refiere sobrevivir sistémicamente. 
"El realismo estructural presenta un retrato sistémico de la política internacional que representa las unidades componentes de acuerdo con la forma de su disposición. Con el propósito de desarrollar una teoría, los Estados se presentan como actores unitarios que desean al menos sobrevivir y se consideran las unidades constituyentes del sistema” (Waltz, 1988b: 618).
Así, el Estado tiene un papel central en tanto que es parte primordial de un sistema que formado por un conjunto de otras unidades estatales, tanto como para la supervivencia (vida del Estado), como para la estabilidad sistémica (equilibrio natural entre otros Estados).

\section{Metáforas naturales}

El balance de poder ha estado asociado a la idea de alianzas antihegemónicas - para que no exista un gran poder que domine todo- o a la acción de los países para mantener su seguridad uniéndose a otros. Pero el concepto de balance de poder es una metáfora que performa cognitivamente como pensamos el mundo, y "tiene la habilidad de transformar el significado establecido de un concepto y cumple el rol esencial de comprender aspectos del mundo" (Little, 2007, p. 23). Metáforas en ciencia, y entre disciplinas científicas han sido de uso recurrente para explicar fenómenos, como aquellas que pasan desde la física o la biología a las ciencias sociales (Palma, 2004). Desde una perspectiva positivista, el balance de poder puede ser visto como central y controvertido, porque si bien ha sido puesto como un término clave e indiscutido que se fundamenta en mitos de equilibrio de adversidad y asociación política (Little, 2007, p. 86).
Thomas Kuhn denominó Revolución Copernicana a la nueva concepción del universo conocido, que cambió radicalmente las concepciones en la astronomía y otras áreas del saber científico, transformando el "concepto del universo que tenía el hombre hasta aquel momento y de su propia relación con el mismo"(Kuhn,1978, p.23). El mundo que concebía la humanidad pasó de ser un intrincado mundo de dos esferas, cuyo centro era la Tierra, para pasar a uno en que todo gira alrededor del Sol. ¿Qué lugar tendrían las concepciones de poder divino, el poder de la Iglesia en Roma, el funcionamiento de las cosas, si ahora había que pensarlo todo de nuevo? Esto llevó a repensar una serie de marcos conceptuales que distintos filósofos y científicos llevaron a cabo revolucionariamente. Se pasó de un todo finito y cerrado, jerárquicamente ordenado, en el cual había perfección celestial, a una "destrucción del Cosmos y de 
Realismo y Relaciones Internacionales: una observación desde la historia de la ciencia y la epistemología

la infinitización del universo" (Koyré, 1999, p. 6).

Esta conceptualización de la realidad internacional tiene su origen en categorías creadas para comprender la naturaleza. Las premisas del orden internacional del siglo xvi eran de origen divino, siendo la autoridad legitimada y explicada por el Dios. Ya en el siglo XviII eran las de un mecanismo gigante, las de la filosofía de Copérnico, Galileo, Boyle, Descartes y Newton, entre otros,

"una máquina o un reloj, creado y mantenido en movimiento por un relojero divino (...) Sin embargo, en los tiempos del Congreso de Viena la imagen del balance gobernado por leyes mecánicas y deterministas fueron desplazadas por la noción de que los humanos pueden aprovechar el poder del conocimiento para entender y manipular las leyes de la naturaleza" (Allan, 2018, p. 1).

Más adelante, a mediados del siglo xIx, las ideas de Darwin eran usadas para "conceptualizar el mundo con ideas evolutivas" (Allan, 2018, p. 2), de supervivencia del más apto, de desarrollo, y racismo en la cual algunas naciones en un contexto imperialista llevaban progreso, mientras que otras estaban atrasadas (Hobsbawm, 1998, p. 67; p. 263). Allan (2018, p.4) llama a este proceso "un cambio cosmológico en las imágenes del universo y el rol de la humanidad en el cosmos que hicieron surgir las ideas científicas y jugaron un rol central en los cambios discursivos de la moderna política internacional".
No obstante, creemos que estas metáforas e ideas fueron trasladadas desde la astronomía, la física y más adelante la biología, y que son un corpus que busca dar la legitimidad natural al orden establecido. Fue también trasladado a todo un campo del conocimiento, las Relaciones Internacionales, y a la Teoría Realista en particular, que busca contextuar cómo el mundo es en realidad y qué deberían hacer aquellos que aspiran a hacer y tener lo que otros hacen y tienen. Como se ve, estos conceptos que vienen del Realismo, pretenden cientificidad, neutralidad, racionalidad y poder explicativo, solo reproducen concepciones de mundo generadas a partir del siglo xviII para justificar el poder de las unidades estatales monárquicas y absolutistas que, con cuyos logros e imágenes de una época en que el poder se secularizaba, representaban el mundo en el que gobernaban. No lo hacían solo por derecho divino, sino en sintonía con las leyes objetivas de la naturaleza. El propio Hans Morgenthau, con una mirada crítica, da cuenta de esto otorgándole al estudio de las ciencias sociales la racionalidad positivista aunque estas no hayan alcanzado aún el grado de predicción de los fenómenos estudiados como aquellos que estudiaban los filósofos naturales y astrónomos del los siglos xvir y xviII (Morgenthau, 1947). La noción de racionalidad que será constitutiva de la modernidad se fundará en estos valores, en el cual el mundo empieza a mecanizarse y matematizarse. La revolución científica 
vino después a generar cambios epistemólogicos cuyas características fueron la "(i) geometrización del tiempo y el espacio; (ii) la reducción cartesiana del universo a materia, movimiento y leyes; (iii) la conformación de una nueva noción de experiencia que incorpora la noción de experimento asociada al uso de instrumentos (...); (iv) la configuración de la escena pública de experimento como el lugar de producción social de objetividad (...)" (Hurtado, 2019, p. 55).

Según Wendt, la anarquía es lo que los Estados hacen de ella. El autor se posiciona desde el constructivismo en Relaciones Internacionales y señala que el debate entre realistas y liberales giraba en torno a si está influenciado por la estructura, la anarquía y la distribución de poder, o por el proceso y las instituciones. En ese sentido, la falta de autoridad política central no obligaría a los Estados a desempeñar una política de poder, y nada hay de inmutable en la anarquía internacional. Es una construcción social. ¿Pero cuál? Si bien el debate entre realistas y liberales sobre cómo mirar el mundo difiere en las perspectivas, ambas teorías suponen racionalidad de los actores en base a sus intereses, pero no mira las identidades que los construyen (Wendt, 2005, p. 2). El autor acierta en que se trata de una construcción social, pero no la identifica como un constructo de ideas de la filosofía natural provenientes del Renacimiento europeo aplicadas a lo internacional. En primer lugar, porque todos toman a los Estados como el principal actor del sistema internacional, porque este presupone relaciones entre un Estado con otro, nacido en Westfalia a mediados del siglo xvI.

Otros enfoques como la geopolítica crítica nos presenta una serie de elementos conceptuales para salir de esta mirada centrada en los mitos westfalianos. "La geopolítica se trata sobre la organización política del espacio y cómo este es concebido, representado y utilizado en la arena política" (Dalby, 2009, p. 234). El lugar responde la geopolítica a otras disciplinas, es importante para entender los procesos políticos, creadora de sentido común. "La imaginación geopolítica moderna ha dado sentido y racionalidad a las prácticas de las élites políticas"(Agnew, 2005, p. 11). Ciertamente, el enfoque realista ha dominado la disciplina desde la década de 1950, en particular en los Estados Unidos, proveyendo un marco analítico para la política exterior dominada por el inmenso poderío militar y económico adquirido, "para los tomadores de decisiones del Estado e investigadores urgidos por la necesidad de teorías sobre la guerra y el poder que fueran convenientemente aplicables de la conducta de la política exterior" (Dalby, 1991, p. 262). Esto le dio justificación a una pléyade de autores como Henry Kissinger o Zbigniew Brzezinski, cuyo realismo de política exterior era prácticamente sinónimo de una polisémica concepción sobre la geopolítica. A través del discurso, los Estados actúan con 
Realismo y Relaciones Internacionales: una observación desde la historia de la ciencia y la epistemología

ciertos preconceptos geográficos que explican la política exterior y le dan sentido, que "espacializan la política internacional caracterizada por lugares, pueblos y sus dramas" (O'Tuathail
\& Agnew, 1992, p. 192). Westfalia, realismo, geopolítica en sentido de gran juego mundial entre potencias, son todos presupuestos y representaciones hobbesianas sobre el Estado.

\section{HOBbES Y EL PODER}

El realismo es presentado muchas veces como una teoría hobbesiana, tributaria de esa tradición de la filosofía política. La filosofía hobbesiana parte de las sensaciones del cuerpo del hombre y llega al Estado. Con la sensación y la imaginación el hombre produce signos voluntarios que llevan al entendimiento. Un signo es un acontecimiento antecedente del consiguiente. "Cuanto más frecuentemente han sido observadas, tanto menos incierto es el signo, y (...) dispone de más signos para avizorar el tiempo futuro" (Hobbes, 1998, p.19). Por lo tanto, la prudencia es una presunción de cómo será el futuro basada en el pasado. El uso de la razón es el resultado aritmético de las palabras y signos, siendo esta exacta. En un pacto, hay razón y acuerdo entre las partes sobre lo convenido. Si Dios entregó al hombre la capacidad de la razón, y hay leyes naturales, no es sino con el uso de la misma y la prudencia cuando se logran los objetivos de las personas. "El éxito continuo en la obtención de aquellas cosas que un hombre desea (...) es lo lo que los hombres llaman felicidad" (Hobbes, 1998, p. 50). ¿Cómo se relaciona esto con el poder? "El poder de un hombre
(...) consiste en sus medios presentes para obtener algún bien manifiesto en el futuro (...) El mayor de los poderes humanos es el que se integra con los poderes de varios hombres unidos por el consentimiento en una persona natural o civil; tal es el poder de un Estado" (Hobbes, 1998, p. 69).

El poder estatal, conseguido con el pacto, tiene lugar en la confianza de entregarle funciones al Leviatán en un contexto de desconfianza mutua que lleva a la guerra civil. Mientras "los hombres viven sin un poder común que los atemorice a todos, se hallan en la condición o estado que se denomina guerra; una guerra tal que es la de todos contra todos" (Hobbes, 1998, p.102). Este conflicto perdurará mientras exista la más mínima voluntad de luchar. Por lo tanto, no hay paz ni seguridad, lo que impide la industria, la agricultura, la navegación o el comercio, la cultura. El filósofo explica que "existe continuo temor y peligro de muerte violenta, y la vida del hombre es solitaria, pobre, tosca, embrutecida y breve" (Hobbes, 1998, p.103). Entonces, cada Estado se presenta como un actor antropomórfico, y se dice que Francia firma la paz, que Inglaterra declara la 
guerra y la "soberanía constituida de ese modo asume la personalidad de todos" (Foucault 1996, p. 81), como si fueran un ser viviente, con voluntad (Escudé, 1992, p. 51). Esta imagen de los hombres que hace necesario un Estado, en contexto de guerras civiles europeas, están contextualizadas en el nacimiento del Absolutismo, proceso por el cual existió "un desplazamiento de la coerción política en un sentido ascendente hacia una cima centralizada y militarizada" (Anderson, 1979, p. 14).

Sin embargo, la literatura especializada olvida el rol de Hobbes como filósofo natural y la posible razón es que los historiadores de la ciencia rescatan a Boyle, con quien este discutía sobre la naturaleza, la ciencia y la experimentación. Una propuesta interesante es la lectura del principal texto hobbesiano como uno de filosofía natural y de epistemología.

"En tanto que tratado de filosofía política, el Leviatán tenía por objeto mostrar las prácticas que habrían de garantizar el orden en el Estado. Este orden podía ser amenazado (...) por intelectuales clericales que se arrogaban una autoridad civil (...) Hobbes trabajó para demostrar el absurdo de una ontología apoyada en sustancias incorporales y espíritus inmateriales. De tal modo, construyó una ontología plenista y en el proceso erigió una teoría materialista del conocimiento, en la cual los fundamentos del conocimiento eran nociones de causas, y dichas causas eran la materia y el movimiento (Shapin y Schaffer, 2005, p. 49).

Thomas Hobbes estaba en desacuerdo con Robert Boyle, quien afirmaba que conocimiento adecuado en la filosofía natural debía ser necesariamente generado a través del experimento, es decir, que los hechos de la naturaleza puedan ser reproducidos a través de la experimentación. Hobbes pensaba que nunca sería posible llegar a un grado de certeza con este método (Shapin y Schaffer, 2005, p. 53). Epistemológicamente, esto cuestiona la idea del hecho experimental, cuyo resultado valida el hecho, y lo niega si no puede realizarse. En el hecho está la experiencia empírica. El debate entre Hobbes y Boyle sobre la bomba de vacío es ilustrativo de ello, pues era una tecnología material. "Los hechos en la nueva neumática de Boyle eran producidos con una máquina. Su filosofía mecánica utilizaba la máquina no solo como metáfora ontológica sino también, crucialmente, como medio para la producción intelectual" (Shapin y Schaffer, 2005, p. 58). Además, Shapin y Schaffer (2005, p. 68) sostenían que "el poder de los nuevos instrumentos científicos, el microscopio y el telescopio, tanto como la bomba de vacío, residía en su capacidad para reforzar la percepción y para constituir nuevos objetos perceptibles", buscando agrandar el dominio de los sentidos y la experiencia.

¿Pero qué era el vacío? Boyle lo entendía "no como un espacio donde no hay cuerpos de ningún tipo, sino un espacio carente o casi totalmente 
Realismo y Relaciones Internacionales: una observación desde la historia de la ciencia y la epistemología

desprovisto de aire" (Shapin y Schaffer, 2005, p. 83).Él no pretendía establecer si existía el éter en ese vacío, pero sí le importaba si tenía efectos experimentales y si se valía de las tres tecnologías experimentales, la material para reproducir el hecho, la literaria para anotarla, y la social para atestiguarla. Sin embargo, para Hobbes el uso de la palabra vacío "debía significar un espacio verdaderamente vacío" (Shapin y Schaffer, 2005, p. 173) y, por lo tanto, la bomba no podía producirlo, buscando demostrar en el debate que alguna sustancia invisible a los ojos estaba presente allí, porque no existen los espacios vacíos. Este punto es crucial para comprender lo fundamental de la forma de ver el mundo de un realista: que la naturaleza aborrece el vacío. Esta aversión tiene muchas explicaciones y se remonta a visiones del mundo natural de la Grecia Clásica de hace dos mil años (Massana et. al., 1997). En la filosofía natural estaban las ideas griegas antiguas de los elementos tierra, agua, aire y fuego. La tierra y el agua son elementos pesados, que tienden a bajar. En cambio, el aire y el fuego tienden a subir. "Pero los cuerpos celestes, incluyendo el Sol, las estrellas y los planetas, están hechos de un quinto elemento -la "quinta esencia" o "éter"- que es una clase de materia incorruptible, sometida a principios físicos diferentes"(Shapin,2000,p.44).
De acuerdo a Shapin y Schaffer (2005, p. 449), "las soluciones al problema del conocimiento son soluciones al problema del orden social", y el debate sobre la bomba de vacío entre Hobbes y Boyle era sobre aquello que el conocimiento es y que es, por otro lado, absurdo. El lenguaje filosófico y científico utilizado por ambos era uno que se trasladaba al lenguaje del orden político. La visión aristotélica planteaba que: "1) la existencia del vacío es absurda porque implicaría la penetrabílidad de la materia; 2) su existencia es vana porque no habría razón para diferenciar el vacío de las dimensiones ocupadas por un cuerpo; 3) la existencia del vacío es imposible porque impediría el movimiento" (Manzo, 2003, p. 68). El vacío se trasladó también como metáfora a la política: el vacío de poder. Si es absurdo pensarlo e imposible concebirlo, y son los Estados quienes llenan los lugares según la concepción realista, entonces donde un Estado no está, aparece otro a ocupar un lugar (Morgenthau, 1986, p. 121). Como hay varios actores haciendo cumplir ese rol "natural" del ambiente internacional, evidentemente el equilibrio deberá primar para la estabilidad, o un equilibrio natural, cual reloj mecánico. No obstante, la filosofía aristotélica proponía distinguir entre lo natural y lo artificial (Shapin, 2000, p. 52). 


\section{EL RELOJ, EL RELOJERO Y LA VIDA}

Las explicaciones científicas de los albores del Renacimiento siempre ponían a Dios como gran creador del mundo. Pero las metáforas fueron evolucionando. Una de las más importantes era la del reloj mecánico que explicaba el funcionamiento del mundo. Shapin (2000) planteaba que se daba un uso importante a las metáforas mecánicas para interpretar fenómenos naturales, y se despersonalizaba el conocimiento de la naturale$\mathrm{za}$, separando sujetos de objetos. Esto es muy importante para comprender la episteme atrás del Realismo como teoría, puesto que los Estados, ante una naturaleza dada e inmutable, no pueden sino actuar en pos de ella, y nunca en su contra. Filósofos que buscaban conocer las causas de las cosas naturales también pensaban la política y el conocimiento natural aspiraba a usarse para "conseguir fines morales, sociales y políticos” (Shapin, 2000, p. 31). En definitiva, como planteaba sobre la práctica científica Prestre (2005, p.26) "fue siempre del más alto interés para los poderes políticos, económicos y militares”. Dominar la naturaleza no solo implicaba conocer los propósitos del orden divino, sino tenía un sentido útil, práctico. El conocimiento geográfico permitía apropiarse del territorio, servía para las artes de las maniobras militares. Los saberes sobre óptica no fungían meramente de observadores celestes, sino como catalejos para el avistamiento lejano en batalla, para la protección estratégica de ciudades. La astronomía no tenía solamente el propósito del conocimiento estelar, sino que era la guía de los navíos comerciales en alta mar que enriquecía a quienes financiaban dichas empresas. Las leyes de física también aportaron al conocimiento de las nuevas artes guerreras, lo mismo que la química a los materiales, tanto para la economía como para su uso bélico. En ese sentido estaba enmarcada la institución del mecenazgo antes de la formación del Estado moderno (Biagioli, 2008), pero también en nuestros tiempos, $\mathrm{y}$ especialmente después de la Segunda Guerra Mundial, en que la ciencia se vio al servicio del poder como una frontera sin fin (Bush, 1999) y desarrollo estatal en pos de la Big Science (Pestre, 2005; Echeverría, 2005).

Si la ciencia y sus problemas están ligados al orden político y sus propósitos, y traslada sus metáforas, las explicaciones basadas en dichas construcciones metafóricas pueden encubrir una falsa noción de explicación y causalidad. El equilibrio de poder ayuda a interpretar pero no lo explica; ordena el mundo para la interpretación de los científicos sociales del ambiente internacional que encubren relaciones de poder. Lo que sí se puede explicar son sus intenciones tras esas metáforas. En efecto, el tan buscado equilibrio de poder por los realistas, y que es dado por 
Realismo y Relaciones Internacionales: una observación desde la historia de la ciencia y la epistemología

hecho (Morgenthau, 1986, p. 222), es producto de las élites políticas que de la realidad hacen un mapa estratégico global (Tuathail, 1994, p. 263), siendo la geopolítica un discurso de expertos (Tuathail et al.,1998, p.3).

El realismo epistémico postula conocer la naturaleza humana y de las cosas, y separa al sujeto de los objetos (Grimaltos, 1988; Dreyfus \& Taylor, 2015; Yuan, 2017). Los realistas en Relaciones Internacionales ven una realidad objetiva y dada de Estados que luchan por el poder, independientemente de otras relaciones sociales. Ahora bien, el llamado Realismo Clásico de Morgenthau postula la idea de que son los Estados, a través de sus gobernantes, los que accionan su poder en la política exterior, con lo que podríamos decir que tienen algún nivel de agencia en cuanto a su capacidad de actuar y transformar el ambiente. Sin embargo, el Neorealismo plantea que es la estructura la que condiciona a los actores de la política internacional, la anarquía, la autoayuda, el equilibrio (Buzan et al., 1993), y que garantiza la estabilidad en el sistema internacional (Niou et al., 1989).

Morgenthau (1986) anclaba su argumentación en un fuerte darwinismo social en el cual "los impulsos a vivir, procrear y dominar son comunes a todos los hombres". Para este influyente autor, en los pensadores realistas existe una analogía de las necesidades y el comportamiento humano a la de los Estados por esta especie creada. El Estado no es más que una extensión política de estas necesidades. Autores precursores de la geopolítica clásica como Ratzel o Kjellen tenían una concepción orgánica y del espacio vital, Mackinder tenía basamentos en Darwin, y Haushofer, que fue un geopolitólogo del nazismo y que propugnaba por un Lebensraum para Alemania, decía que utilizaba "deliberadamente analogías biológicas porque las fronteras son organismos biológicos del Estado" (Rattenbach, 1985, p. 92). De estas visiones se han nutrido amplias visiones académicas realistas actuales amplias visiones académicas realistas actuales.

Kenneth Waltz tiene una visión positivista desde su aproximación Realista. Él persigue una metodología con pretensiones de poner a prueba la teoría, inferir hipótesis a pruebas experimentales o de observación, eliminar o controlar variables, y revisar si la teoría tiene poder explicativo (Waltz, 1988a, p. 26), asimilando los hechos de la naturaleza a los hechos de la política internacional. "En una teoría sistémica, parte de la explicación de las conductas y de los resultados se halla en la estructura del sistema. Una estructura política es semejante a un campo de fuerza en física" (Waltz, 1988a, p. 110). ¿En qué manera siquiera se asemejan los códigos de conducta entre varias unidades estatales con las leyes de la gravitación? Es evidente que aquí se está utilizando una metáfora, la cual en este caso posee un rol central: el de hablar de la inevitabilidad del 
comportamiento interestatal. Uno no puede escapar a las leyes de la gravedad y las leyes newtonianas de la atracción de los cuerpos y tampoco de la Anarquía. Por esta razón, se puede prever una regularidad de comportamiento de las unidades que componen la estructura, pero realmente, como es inevitable, da prácticamente por sentado que un Estado o se comporta como se espera que se comporte, o acumula el poder y lo usa -al igual que lo hace la invisible gravitación magnética- o desaparecerá. Es, por lo tanto, una profecía autocumplida que termina justificando el comportamiento de las potencias que conforman el sistema internacional.

Por su parte, Kissinger presenta un planteo desde el punto de vista histórico, y se basa en aquellos planteos y políticas de los policymakers que forjaron la política exterior, de donde se pueden extraer lecciones para tomar decisiones actuales. Los sistemas internacionales tienen una vida determina$\mathrm{da}, \mathrm{y}$ es precaria, pues dura una determinada cantidad de años (Kissinger, 2001, p. 803). El orden europeo pasó de ser un gran mecanismo de relojería newtoniano de partes interconectadas entre sí, y fue reemplazado por un "mundo darwiniano de la supervivencia del más apto” (Kissinger,2016, p. 86).

\section{REFLEXIONES FINALES}

Distintos autores del campo disciplinar de las Relaciones Internacionales han pensado la naturaleza de los hombres, el Estado, la Guerra y las causalidades que a partir de ello se derivan. Sin embargo, pensar la teoría de las Relaciones Internacionales desde una perspectiva Realista puede resultar esencialmente problemático si no se problematiza que sus premisas fueron performadas en torno a metáforas de las ciencias de la naturaleza del siglo xVII, y los aportes que prosiguieron en los siglos subsiguientes. Presuponer que el mundo político puede ser explicado por atributos inmanentes a una naturaleza imaginada posmedieval que acuñaron filósofos naturales, que tenían una visión divina del cosmos, sacralizaban la naturaleza y partían de la premisa de que el todo era creación divina, no parece explicar el hecho social de la competencia entre Estados por su supremacía. Estos atributos naturales otorgaron argumentos a quienes hacían la política para entender el lugar de las potencias y el poder.

Las premisas de las que parte el Realismo son atribuibles a cómo se veía el armónico orden natural en los albores del Renacimiento europeo. Autores como Raymond Aron se preguntaban si es el hombre pacífico o beligerante por naturaleza, pero reconocía en el concepto 'naturaleza' distintos significados. En efecto, los distintos estados de naturaleza de la filosofía política clásica tenían distintos sentidos. Aron identifica relaciones de dicho concepto con diversos enfoques en cuestión, como las raíces biológicas, 
psicológicas, sociales, al hecho social y natural de la guerra que es histórico desde la existencia de los hombres, a mitos de la escencia humana, entre otros (Aron, 2003). En palabras de Wight (1992: 25) "toda teoría política presupone algún tipo de teoría sobre la naturaleza humana, o alguna teoría antropológica básica”. De esta manera, los realistas tienden a encontrar una naturaleza negativa, encontrando pesimismo, maldad, o ambición de poder (Barbe, 1987: 160; Cox, 2013: 136). Otros autores ya postulaban que la escencia del hombre venía de lo espiritual, no de la naturaleza biológica (Sombart, 2006).

Las metáforas basadas en la filosofía natural, astronomía y, más tarde, la biología darwinista, son hechos políticos, parte constitutiva de la cosmovisión de las élites dominantes que le imprimieron, desde la formación del moderno sistema westfaliano y el Estado-Nación, esa particular forma de entender el poder político cual si se tratara de la máxima hermética, "tanto es arriba como es abajo". Consecuentemente, muy similar a la forma de ver el mundo del medioevo, el orden divino tenía su correlato en la morada de los hombres, el orden temporal: el cosmos perfecto tiene su correlato en el orden político. Sin embargo, el conocimiento científico es una cuestión de poder, que justifica para quién y qué orden se desea justificar. El Realismo como teoría política no nos propone cambiar las leyes de funcionamiento, si no ajustarnos a ellas para sobrevivir en un mundo en el cual los fuertes hacen lo que pueden y los débiles sufren lo que deben, al decir de Tucídides. El realismo estructural de Waltz y todos aquellos que siguieron a Morgenthau y teorizaron al paradigma con una visión positivista y sistémica, no dejan de partir de las premisas fundamentales realistas, centradas en el Estado, el poder, la naturaleza humana.

"La ciencia moderna como institución, la que se organiza en los siglos xvi y xviI, fue siempre del más alto interés para los poderes políticos y militares (...). Los saberes permitieron desde hace mucho la concepción de técnicas, de objetos materiales y de armas, que contribuyeron activamente al dominio práctico del mundo, a la producción y a la operación del control político o de las operaciones $\mathrm{mi}$ litares, que fueron decisivas en la reproducción de las élites y en su selección y que ofrecieron ideales y normas, nuevos modos de ser al mundo" (Pestre, 2005, p. 26).

El conocimiento científico y tecnológico ha sido impulsado por el Estado, su principal financiador tanto en ciencias duras como en ciencias sociales, para lograr objetivos de políticas públicas. ¿Qué políticas lograremos en un mundo anárquico centrado en el Estado que busca el poder? El conflicto, inherente a la política, solo podrá resolverse a través de más poder? Los 
que tienen poder, por lo tanto, procurarán los medios para que las cosas cambien lo menos posible. No se trata solo de hacer una lectura crítica a las teorías hegemónicas de las Relaciones Internacionales que tienen una mirada con la centralidad en lo estatal y poder (Ashley y Walker, 1990; Agnew, 2005; Walker, 2010), sino que también es necesario buscar el lenguaje utilizado y el razonamiento sobre cómo se construye la argumentación, y de dónde esta proviene.

No obstante, ¿que el Realismo utilice metáforas invalida el pensamiento científico? De ninguna manera, pues otras disciplinas utilizan metáforas que provienen de otras ciencias. Sin embargo, aquí nos preguntamos sobre su pertinencia y sus consecuencias. Si el universo está determinado por factores inamovibles e inmodificables, como el equilibrio de poder, no queda lugar para transformación alguna.Y el poder, los poderosos, buscan el status quo. Pero, sin embargo, como decía Galileo Galilei, Eppur si muove. Él confirmó que la lente, valga la metáfora de la óptica, con el que se miraba el universo era incorrecto. La Iglesia, el poder, sostenía el sistema de Ptolomeo que situaba a la Tierra como centro.Siglos más tarde, todos aceptaron la lente de Copérnico. La naturaleza puede o no aborrecer el vacío. Pero en política internacional los actores no ocupan, necesariamente, el espacio vacío dejado por otros, simplemente porque no hay espacios vacíos. Las Relaciones entre Estados no son un derivado de la Selección Natural ni de la armonía universal astronómica, sino políticas de poder que llevan a cabo personas con intereses. Quizás otras metáforas deberían adornar las explicaciones de naturaleza geopolítica.

\section{BibLIOGRAFÍA}

Agnew, J. (2005). Geopolítica. Una re-visión de la política mundial. Madrid: Trama.

Aron, R. (2003). Peace \& War. A theory of International Relations. New York: Routledge.

Ashley, R. y Walker, R. (1990). "Speaking the language of exile: dissent though in International Studies”, International Studies Quarterly, 34 (3).

Allan, B. (2018). Scientific Cosmology and International Orders. Cambridge: Cambridge University Press.
Anderson, P. (1979). El Estado Absolutista. Madrid: Siglo XXI.

Barbe, E. (1987). El papel del realismo en las relaciones internacionales (La teoría de la política internacional de Hans J. Morgenthau). Revista de Estudios Politicos, 57. https://recyt.fecyt.es/index.php/ RevEsPol/article/view/48299

Biagioli, M. (2008). Galileo cortesano. La práctica de la ciencia en la cultura del absolutismo. Madrid: Katz. 
Realismo y Relaciones Internacionales: una observación desde la historia de la ciencia y la epistemología

Bush, V. (1999), "Ciencia, la frontera sin fin. Un informe al presidente, julio de 1945 ”. REDES №14.

Buzan, B.; Jones, C. y Little, R. (1993). The Logic of Anarchy: Neorealism to Structural Realism New directions in world politics. New York: Columbia University Press. Cox, R.W. (2013). Fuerzas sociales, estados y órdenes mundiales: Más allá de la Teoría de Relaciones Internacionales. Relaciones Internacionales, (24), 99-116. https://revistas.uam.es/relacionesinternacionales/ article/view/5195

Dalby, S. (1991). Critical Geopolitics: Discourse, Difference, and Dissent. Environment and Planning D: Society and Space, 9(3), 261-283. https://doi. org/10.1068/d090261

Dalby, S. (2009). Geopolitics, the revolution in military affairs and the Bush doctrine. International Politics 46 (2/3), 234-252.

Dolman, E. (2005).Astropolitik. Clasical geopolitics in the space age. London: Frank Cas.

Dougherty, J. y Pfaltzgraff, R.(1993). Teorías en Pugna en las Relaciones Internacionales. Buenos Aires: Grupo Editor Latinoamericano.

Dreyfus, H. y Taylor, Ch. (2015). Retrieving Realism. Harvad University Press: London.

Escudé, C. (1992). Realismo Periférico. Fundamentos para la nueva política exterior argentina. Buenos Aires: Planeta.

Echeverría, J. (2005). La revolución tecnocientífica. CONfines de relaciones internacionales y ciencia politica, 1(2), 09-15. http://www.scielo.org.

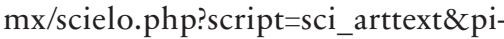

$\mathrm{d}=$ S1870-35692005000200001\&lng=es\&t$\operatorname{lng}=\mathrm{es}$

Foucault, M. (1996). Genealogía del Racismo. La Plata: Altamira.

Grimaltos, T. (1988). Hacia un realismo epistémico en filosofía de la percepción, Quaderns de filosofia i ciència, 13/14: 81-106. Hobbes, T. (1998). Leviatán o la materia, forma y poder de una República, Eclesiástica y Civil. México: Fondo de Cúltura Económica.

Hobsbawm, E. (1998). La Era del Imperio, 1875-1914. Buenos Aires: Crítica.

Hurtado, D. (2019). "De la Mecánica de Newton al imperio de los economistas", en Kozel, A.; Bergel, M. y Llobet, V. El futuro. Miradas desde las Humanidades. San Martín: UNSAM Edita.

Kissinger, H. (2016). Orden Mundial: reflexiones sobre el carácter de las naciones y el curso de la historia. Barcelona: Debate.

Kissinger, H. (2001).La Diplomacia. México: Fondo de Cultura Económica.

Kuhn, T. (1978).La Revolución Coperniacana. Volumen 1. Madrid: Hispamérica.

Koyre, A. (1999).Del Mundo Cerrado al Universo Infinito. Madrid: Siglo XXI.

Little, R.(2007). The Balance of Power in International Relations: Metaphors, Myths and Models. Cambridge: Cambridge University Press.

Manzo, S. (2003). La naturaleza y sus fines en la discusión sobre el vacío desde el siglo XIII hasta el siglo XVII. Patristica Et Mediavalia, 24, 65-89. https://doi. org/10.34096/petm.v20037861

Massana, A., Jou, D., \& Torras, J. (1997). Historia del vacío. El Ciervo, 46(552), 4-9. www.jstor.org/stable/40817642 
McGlinchey, S., Walters, R. \& Gold, D. (2017). International Relations Theory. Bristol: E-International Relations Theory Publishing. http:/www.e-ir.info/ wp-content/uploads/2017/11/International-Relations-Theory-E-IR.pdf

Morgenthau, H. (1986). Política entre las Naciones. La lucha por el poder $y$ la paz. Buenos Aires: Grupo Editor Latinoamericano.

Morgenthau, H. (1947). Scientific Man vs. Power Politics. London: Latimer House.

Niou, E.; Ordeshook, P. y Rose, G. (1989). The Balance of Power: Stability in International Systems. Cambridge: Cambridge University Press.

Palma, H. (2004). Metáforas en la evolución de las ciencias. Buenos Aires: Jorge Baudino Ediciones.

Prestre, D. (2005). Ciencia, dinero y política. Ensayo de interpretación. Buenos Aires: Nueva Visión.

Rattenbach, A. (1985). (comp.). Antología Geopolítica. Buenos Aires: Editorial Pleamar.

Ray, A.(2003). International Relations: A critique of the Realist theory. India International Centre Quarterly, 30(2), 110128. Retrieved July 1, 2020, from www. jstor.org/stable/23006110

Rodrigues, T. (2013). Agonismo y genealogía: Hacia una analítica de las Relaciones Internacionales. Relaciones Internacionales, 24. https://revistas.uam. es/relacionesinternacionales/article/ view/5193

Shapin, S. (2000). La revolución cientifica. Una interpretación alternativa. Barcelona: Paidós.
Shapin, S. y Schaffer, S. (2005). El Leviatán y la bomba de vacío. Hobbes, Boyle y la vida experimental. Bernal: Universidad Nacional de Quilmes.

Sombart, W. (2006). Vom Menschen. Versucht einer geistwissenschaftlichen Anthropologie. Berlin: Duncker \& Humboldt.

Tuathail, G., \& Agnew, J. (1992). Geopolitics and discourse: practical geopolitical reasoning in American foreign policy. Political Geography (11). 190-204.

Tuathail, G.; Dalby, S. \& Routledge, P. (1998). The Geopolitics Reader. London: Routledge.

Tuathail, G. \& Toal, G. (1994). Problematizing Geopolitics: Survey, Statesmanship and Strategy. Transactions of the Institute of British Geographers, 19(3), 259-272.

Walker, R. (2010). After the Globe, before the World. London: Routledge.

Waltz, K. (1990). Realist Thought and Neorealist Theory. Journal of International Affairs, 44(1), 21-37. Retrieved August 4, 2020, from www.jstor.org/ stable/24357222

Waltz. K. (1988a). Teoría de la Política Internacional. Buenos Aires: Grupo Editor Latinoamericano.

Waltz, K. (1988b). The Origins of War in Neorealist Theory. Journal of Interdisciplinary History, 18(4), pp. 615-628.

Wendt, Alexander. (2005). La anarquía es lo que los estados hacen de ella:la construcción social de la política de poder | Anarchy is what states make of it: the Social Construction of Power Politics. Relaciones Internacionales, 0(1). Recuperado de https://revistas.uam.es/index. 
Daniel Blinder

Realismo y Relaciones Internacionales: una observación desde la historia de la ciencia y la epistemología

php/relacionesinternacionales/article/ view/4828

Weber, M. (1993). Sobre la Teoría de las Ciencias Sociales. Barcelona: Planeta Agostini.

Wight, M. (1992). International Theory. The Three Traditions. New York: Holmes \& Meier.
Yuan, M. (2017). "El realismo de Wittgenstein y Heidegger". Tesis presentada con el fin de cumplir con los requisitos finales para la obtención del grado de Doctor de la Facultad de Filosofía y Letras de la Universidad de Buenos Aires en Filosofía. 
